\begin{tabular}{|c|c|c|}
\hline ISSN (Online): 2367-6957 & \multicolumn{2}{|c|}{ ISSN (Print): 2367-6361 } \\
\hline & Izvestiya Journal of Varna University of Economics 3 (2020) & IZVESTIYA \\
\hline & IZVEST I Y A & \\
\hline 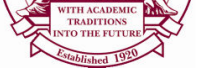 & $\begin{array}{c}\text { Journal of Varna University of Economics } \\
\text { http://journal.ue-varna.bg }\end{array}$ & 19 \\
\hline
\end{tabular}

\title{
WINE PURCHASING DRIVERS OF YOUNG BULGARIANS - AN EMPIRICAL STUDY
}

\section{Petyo BOSHNAKOv ${ }^{1}$, Irina KANCHEVA ${ }^{2}$, Georgi MARINOV ${ }^{3}$}

\footnotetext{
${ }^{1}$ Department of International Economic Relations, University of Economics, Varna, Bulgaria. Email: pboshnakov@ue-varna.bg

2 Department of International Economic Relations, University of Economics, Varna, Bulgaria. Email: irina_kancheva@abv.bg

${ }^{3}$ Department of International Economic Relations, University of Economics, Varna, Bulgaria. Email: gmarinov@ue-varna.bg
}

JEL: D12, Q13, Q17

Key words:

Bulgarian Generation Z, alcohol purchases, decision-making process, bottled wine purchases.

\begin{abstract}
In recent years there has been a generational shift, and wine consumption of Generation $\mathrm{Z}$ is emerging. In our study we aim to explore the main drivers of wine purchase decisions of young Bulgarians. We explored a sample of 176 Bulgarian residents, aged 19-25, living in Northeastern Bulgaria. The results of our study show that in their wine consumption young Bulgarians are not differentiated by variables like sex, place where they live and living in couples or single. Among the main sources of difference in the perceptions of young Bulgarians towards wine are their predisposition to buy expensive wines and the practice to mix wine drinking with the drinking of other alcoholic beverages.
\end{abstract}

(C) 2020 University of Economics - Varna

Citation: BOSHNAKOV, P., KANCHEVA, I., MARINOV, G. (2020). Wine Purchasing Drivers of Young Bulgarians - an Empirical Study. Izvestiya Journal of Varna University of Economics, 64 (3), p. 328 - 340. DOI: 10.36997/IJUEV2020.64.3.328

\section{Introduction}

In our study, we aim to explore the driving forces in wine purchases of young Bulgarians (aged 19-25). This age group falls within the emerging wine consumers, 
and given that the legal age for drinking in Bulgaria is 18, the respective individuals are part of a young generational cohort. A generational cohort is a group of individuals who are born in the same time period and share similar experiences due to the influence of same external events during their life, and developing unique values, preferences, attitudes and buying behaviour that remain over a lifetime (Schewe and Meredith, 2004). Established in the U.S., the principal generational cohorts are used around the world. Common beliefs about generations are that they differ as characteristics, lifestyles, and attitudes of the group, and should be treated differently by marketers (Williams and Page, 2011). We explore the Generation Z, a global and diverse generation, who lived its entire life with the Internet, accustomed to multiple information sources and to a flood of messages.

Our study reveals some of the purchasing patterns concerning some primary points in the decision process.

The rest of the paper is organised as follows: section 2 represents a literature review, section 3 describes the methodology used, section 4 is a discussion of results, section 5 outlines conclusions drawn from the study.

\section{Literature review}

Generation Z, or Gen Z for short, is the demographic cohort succeeding the Millennials, or Gen Y (Turner, 2015; Wood, 2013; Dolot, 2018). Demographers and researchers typically use the mid- to late-1990s as starting birth years, while consensus has not been reached on the ending birth years. Generation $\mathrm{Z}$ is regarded as substantial part of emerging, newer consumer segments. For most practical tasks, it is comprised of persons born after the mid-1990s (Williams and Page, 2011; Dimock, 2019) and consists of individuals in their formative years. Cutoff points are not exact, but for analytical purposes mid-1990s are meaningful, due to the formatively acting key political, social and economic factors for the generation. Key features of Generation $\mathrm{Z}$ differ from previous generations, thus an exploration of its purchase drivers makes sense.

Priporas, Stylos and Fotiadis (2017) argue that members of the young generation seem to behave differently as consumers and are more focused on innovation. Therefore an enhanced smart retailing experience may be important for wine promotion.

Exploring the Generation Z wine consumers, Bede, Massa and Maumon (2019) underline the central role of the 'pivot' generation (the 30-65 age group) concerning wine-related learning and education. However, their study is undertaken in France, a country with very strong wine production and consumption traditions, and the 
discovered tendency of this generation to maintain Old-School values and to construct themselves by active learning may not be the case for other countries. These findings are in line with the general characteristics of Generation $\mathrm{Z}$ found by Dolot (2018), that members of this generation perceive the communication process as bidirectional they give feedback, but they also expect feedback. Wine-based studies underline that motives for consumption are related to the joy of the taste of wine, the related social aspects, lifestyle patterns and factors like health concerns.

Exploring US respondents, Chang, Thach and Olsen, (2016) find differences between generations in concerns about health, in general it is believed that wine is a healthier beverage than beer or spirits. Also found is that health consciousness appears to have a strong influence on personal choices related to food and beverage consumption, with health consciousness increasing among newer generations. Thach, Riewe and Camillo (2020) find that Generation Z US individuals in their wine consumption are much more engaged in social platforms.

From the level of expertise, wine quality is assessed at two levels: from the viewpoint of wine makers and experts and from the viewpoint of the consumers, as Vannevel et al. (2018) underline. Most wine consumers are not experts, therefore the quality perception process is important for marketers, with quality being a multidimensional construct. Consumers want and need to receive more detailed information about wine, from the ingredients used to the wine-making process, about brand history, and sustainability (Castellini et al., 2014; Castellini and Samoggia, 2018).

For people of Generation Z, Foroudi et al. (2019) find interesting changes in wine consumption, concerning the country-of-origin effect. Their results suggest the existence of wide possibilities for educational marketing initiatives. In their experiment, half of the participants changed their opinion on the preferred wine after receiving more information about the notion of wine quality.

New formats are of interest for the contemporary marketers (Castellini and Samoggia, 2018) - among new types of offer there is different packaging (bag in box, small six-pack bottled wines, each $1 / 4$ of the traditional bottle, wine in cartons, bags or cans are among the variety of variants), different colours and flavours (i.e. blue wine, taste of mocha or vanilla etc.), different types of wine (i.e. low alcohol, $8 \%$ ).

France and Italy are among the world's leaders in wine production, Italy quantitatively, and France commercially (OIV, 2019; Nelgen and Anderson, 2011). The countries are regarded as global 'extreme cases'. Prices differ roughly twice, with average French wine prices being about the double of average Italian wine prices (for details, see i.e. Nomisma, 2017). For Italy, Castellini and Samoggia (2018) find a 
statistically significant relationship between experiencing wine as a special drink, convivial drink, easy to purchase, recommended and online purchase. Persons neophilic to wine perceive it as a social and accessible drink, and are more inclined to purchase it online. Data from Italy (ISTAT, 2020) shows that for the last decade alcohol consumption dropped nearly twice for people under 18 years, but remained in general stable for people of legal age for alcohol consumption, with a slight growth for people aged 18-25.

For Bulgaria and the neighbouring countries, wine culture seems to be low. For Bulgaria, Noev (2005) shows that wine prices are significantly and positively influenced by wine quality. Also shown is that product differentiation is important in transition markets. Lyubenov, Neykov and Vergilova (2016) underline the importance of internationalization in the wine industry for the development of the Bulgarian economy. Good prerequisites for internationalization exist in Bulgaria (Zaharieva et al., 2012). High taxes and resulting high prices could contribute to limiting the consumption of excise goods amongst the young generation (Boneva, 2014).

Vlachvei (2011) finds price for Greece to be one of the most important selfreported criteria of wine selection. For Turkey Gunay and Baker (2011) argue that demographic profiles influence wine consumption patterns of consumers. They also find the wine market in Turkey is blooming. For Hungary, Szakal (2008) finds that the level of Hungarian wine culture is relatively low and improving the wine culture should be supported. The latest studies have shown that the average consumer in Serbia knows very little about wine, i.e. wine culture (Radovanovic et al. 2017), with demographic factors (gender, age, education) affecting the decision on the purchase of wine, and the age group having the most significant impact on the choice of wine.

Using a questionnaire survey and a biometric method - eye-tracking, Nemcova and Bercik (2019) find that information on a label (brand, variety etc.) is the most important factor influencing the selection of wine for young people in Slovakia. Szabo (2019) argues that event marketing, incl. wine tourism and wine events are among the most efficient ways to introduce wines to international consumers.

Culture and attitudes strongly influence the consumption of wine. Wine is among the markers of cultural identity for countries like Bulgaria and Romania, it is regarded as an "asset" (Kaneva and Popescu, 2011). Wine is a very important part of agriculture in Bulgaria - the country is among the top 10 as share of total agricultural crop area under vines (Anderson and Nelgen, 2009).

However, wine consumption does not have the same distribution among all the people in a country, with some social categories consuming and spending more money on wine than others. Moreover, ordinary consumers identify wines mainly 
from the well-known origin countries, as Boshnakov and Marinov (2013) show. Consumer expenditure strongly varies also among countries - e.g. for Bulgaria in 2011 wine expenditures were only $11.25 \%$ of alcohol expenditures and $0.308 \%$ of disposable income, representing a contrast even to neighbouring and similar countries: Romania - 23.46\%/0.651\%, Croatia - 46.24\%/0.849\%, Greece $37.08 \% / 0.332 \%$, Turkey $-2.76 \% / 0.005 \%$ (Stancu, 2015). For Bulgaria, a multivariate analysis of data on patterns of alcohol consumption from a multi-stage nationwide survey shows that drinking is less common among the elderly and those who live in villages (Balabanova and McKee, 1999).

\section{Methodology and data collection}

We aim to explore the forces driving wine purchases of young people, therefore we limited the age up to 25 years. Our choice of this upper age limit is motivated by the fact that international classifications associate young people with this age limit i.e. for the purposes of studying unemployment or poverty. In contemporary Bulgarian reality, people below 25 years are at least to some extent dependent on their parents. In many cases the typical high unemployment rate is substituted by university studies - enrolment rates in universities are rather high. There is relatively low marriage rate for this age group, and few young people have their own children. According to official statistics for 2019 (NSI, 2020a), only 25.7\% of the wives, and only $12.8 \%$ of the husbands in new marriages were below 26 years of age. The unemployment rate for young people is also higher than the average for the country $12.5 \%$ vs. $4.6 \%$ total (NSI, 2020b). The mean age of the mother at the first birth in Bulgaria in 2019 was 27.3 years (NSI, 2020c). Therefore our typical respondent is a non-married person, with no children. However, some people of that age do live in couples, our sample covers such cases, too.

Our other age limit (the lower one) is 19 , because in Bulgaria alcohol purchases are not legal below the age of 18 , and since we strive to uncover the purchasing driving forces of young Bulgarians, we believe that one has to have at least one year of possible choices to build some views about what and when to buy, to gain some experience in the matter.

Our sample consisted of 176 Bulgarian residents, aged 19-25, living in Northeastern Bulgaria, 127 women and 49 men, all of them having at least a secondary education, 144 of them living in a city, and 32 living in a small town or village.

The study was conducted online, in the period February-March 2020, in choosing our respondents we used the "snowball" sampling method, thus our sample is of convenience type. 
The questionnaire consists of 4 classification questions (sex, age, years of living as a couple or marriage, place of living) and 19 closed answers questions and Likerttype items, covering various aspects of the drinking and purchasing habits of the respondents. For the Likert-type items, we do offer a neutral option, so that the answers are obtained with no "forced choice". However, the weakness of our method is the possible undecidedness of the respondents.

To explore the driving forces in wine purchase decisions we use a bunch of 9 questions, covering the consumer's preferences for wine in relation to variety, country of origin, type of wine (dry/sweet), price, brand/producer, year, purpose, food and the colour of wine (white/rose/red).

We also ask about the drinking habits of the respondents (whether they can mix drinking of wine with drinking of other alcoholic beverages, whether they drink wine in a non-typical manner, i.e. white wine with red meat, their preferred alcoholic beverage), their typical wine preferences, their purchasing habits (frequency of wine purchases, frequency of higher grade wine purchases, typical price of purchased wine, last wine bought).

We aim to make different cuts of data in order to form clusters of respondents using the drinking habits as pivots.

Given that our collected data consists of ordinal values, we are limited to the usage of non-parametric tests and statistics. In the analysis we use the commonly used classical tests - the chi-squared test, the Mann-Whitney-Wilcoxon (MWW) test (Mann and Whitney, 1947; Wilcoxon, 1945) and the Kruskal-Wallis (KW) test (Kruskal and Wallis, 1952). It has been shown in the literature that using the MWW test in reasonably large samples can take place without loss of power (towards the ttest, for details see de Winter and Dodou, 2010). To measure the effect size, we use the Vargha and Delaney A test (Vargha \& Delaney, 2000).

\section{Results and discussion}

We begin our study with an assessment of the activity of wine purchases. In general, in the whole population of Bulgaria, men drink alcohol more often and in bigger quantities than women, thus our initial expectations were that perhaps men are more likely to buy wine. But in the cohort of young people there is an adverse situation: women appear to be more interested in wine purchases (see Table 1). 


\section{Wine purchases by frequency of purchase}

\begin{tabular}{|l|r|r|r|}
\hline \multicolumn{1}{|c|}{ Frequency of purchases } & \multicolumn{1}{c|}{ Total } & \multicolumn{1}{|c|}{ Women } & \multicolumn{1}{c|}{ Men } \\
\hline Several times weekly & 34 & 32 & 2 \\
\hline 2-3 times per month & 79 & 55 & 24 \\
\hline 2-3 times per year & 43 & 31 & 12 \\
\hline I don't buy & 20 & 9 & 11 \\
\hline
\end{tabular}

Pearson's Chi-squared test shows that differences in purchasing frequencies by sex do exist ( $p$-value $=0.001$ ), with women being more active buyers.

The distribution of the answers to the core questions about purchase drivers (Table 2) demonstrates no contrast situations, there are no overwhelming answers in either direction in any one of the core questions.

Table 2

Distribution of scores given on core questions in the total sample and by sex

\begin{tabular}{|c|c|c|c|c|c|c|c|c|c|}
\hline Score & $\begin{array}{c}\text { Vari- } \\
\text { ety }\end{array}$ & $\begin{array}{c}\text { Ori- } \\
\text { gin }\end{array}$ & $\begin{array}{c}\text { Dry/ } \\
\text { sweet }\end{array}$ & Price & Brand & Year & $\begin{array}{l}\text { Pur- } \\
\text { pose }\end{array}$ & Food & Colour \\
\hline & \multicolumn{9}{|l|}{ Total } \\
\hline 1 & 38 & 35 & 30 & 31 & 24 & 33 & 30 & 33 & 28 \\
\hline 2 & 22 & 21 & 29 & 20 & 27 & 40 & 25 & 28 & 15 \\
\hline 3 & 45 & 56 & 37 & 46 & 50 & 58 & 39 & 42 & 26 \\
\hline 4 & 49 & 49 & 50 & 51 & 44 & 29 & 44 & 48 & 45 \\
\hline \multirow[t]{2}{*}{5} & 22 & 15 & 30 & 28 & 31 & 16 & 38 & 25 & 62 \\
\hline & \multicolumn{9}{|l|}{ Women } \\
\hline 1 & 33 & 27 & 25 & 26 & 20 & 27 & 24 & 25 & 24 \\
\hline 2 & 14 & 17 & 18 & 16 & 21 & 31 & 17 & 22 & 10 \\
\hline 3 & 32 & 39 & 21 & 32 & 32 & 39 & 29 & 28 & 17 \\
\hline 4 & 32 & 33 & 40 & 34 & 32 & 21 & 33 & 35 & 35 \\
\hline \multirow[t]{2}{*}{5} & 16 & 11 & 23 & 19 & 22 & 9 & 24 & 17 & 41 \\
\hline & \multicolumn{9}{|l|}{ Men } \\
\hline 1 & 5 & 8 & 5 & 5 & 4 & 6 & 6 & 8 & 4 \\
\hline 2 & 8 & 4 & 11 & 4 & 6 & 9 & 8 & 6 & 5 \\
\hline 3 & 13 & 17 & 16 & 14 & 18 & 19 & 10 & 14 & 9 \\
\hline 4 & 17 & 16 & 10 & 17 & 12 & 8 & 11 & 13 & 10 \\
\hline 5 & 6 & 4 & 7 & 9 & 9 & 7 & 14 & 8 & 21 \\
\hline
\end{tabular}

Note: 1 - "Not at all", 2 - "Weakly", 3 - "Neither weakly, nor strongly", 4 - "Strongly", 5 - "Very strong". 
More formal tests about the possible differences (Table 3, Mann-WhitneyWilcoxon tests) reveal that in fact neither the sex, nor the origin of last wine bought nor the place of living influence the decision making process - all the test results are non-significant for these variables. Respondents with different couple status (single or living in a couple/marriage) perceive differently the influence of variety and origin of wine when they make decisions about wine purchases. However, strongest differences are discovered between respondents who do not mix and who combine different alcoholic beverages - for all characteristics of wine studied (variety, origin etc.) test statistics are strongly significant.

Table 3

MWW tests for the questions about purchase decisions (p-values)

\begin{tabular}{|l|c|r|r|r|r|r|}
\hline & \multicolumn{1}{|c|}{ Sex } & \multicolumn{1}{c|}{ Single } & \multicolumn{1}{c|}{ Place } & \multicolumn{1}{c|}{ BG/other } & Combine & \multicolumn{1}{c|}{ Expensive } \\
\hline Variety & 0.14 & 0.04 & 0.68 & 0.18 &. & 0.03 \\
\hline Origin & 0.31 & 0.01 & 0.62 & 0.79 & 0 & 0.03 \\
\hline Dry/Sweet & 0.57 & 0.43 & 0.46 & 0.36 &. & 0.00 \\
\hline Price & 0.09 & 0.28 & 0.78 & 0.06 & 0 & 0.96 \\
\hline Brand & 0.40 & 0.11 & 0.53 & 0.16 & .0 .08 \\
\hline Year & 0.07 & 0.24 & 0.29 & 0.28 & 0.43 & 0.00 \\
\hline Purpose & 0.25 & 0.40 & 0.50 & 0.54 & 0.02 & 0.12 \\
\hline Food & 0.48 & 0.23 & 0.42 & 0.09 & 0.01 & 0.00 \\
\hline Colour & 0.19 & 0.46 & 0.86 & 0.11 & & 0.57 \\
\hline
\end{tabular}

Note: in the last three columns there are the results from tests by the last wine bought (Bulgarian or foreign), by whether the respondents mix wine with other alcohol beverages, and by how often they buy wines priced over $15 \mathrm{lv}$.

Another source of differences in attitudes towards wine characteristics is the predisposition to buy expensive wines. Respondents who more often bought wines priced above $15 \mathrm{lv}$., demonstrated differences in their attitudes, compared to the rest of the sample, for most wine characteristics, with the exception of price, brand, purpose and colour.

Established drinking habits may play a significant role in the magnitude of importance of different aspects of wine purchase. People who do not drink wine with other alcoholic beverages have different preferences about wine than those who do mix drinks (with rakia/vodka/beer/cognac/other). All of the test statistics are significant at 0.05 level, with the exception of the test statistics of the production year. 
Table 4

Kruskal-Wallis tests for the questions about purchase decisions (p-values)

\begin{tabular}{|l|r|r|r|r|}
\hline & Most & Favourite & \multicolumn{1}{c|}{ Price } & \multicolumn{1}{c|}{ Foreign } \\
\hline Variety & 0.77 & 0.17 & 0 & 0.11 \\
\hline Origin & 0.47 & 0.10 & 0 & 0.06 \\
\hline Dry/Sweet & 0.56 & 0.26 & 0 & 0.06 \\
\hline Price & 0.41 & 0.65 & 0 & 0.23 \\
\hline Brand & 0.29 & 0.25 & 0 & 0.27 \\
\hline Year & 0.89 & 0.03 & 0 & 0.40 \\
\hline Purpose & 0.35 & 0.35 & 0 & 0.80 \\
\hline Food & 0.73 & 0.78 & 0 & 0.07 \\
\hline Colour & 0.36 & 0.06 & 0 & 0.80 \\
\hline
\end{tabular}

Note: "Most" - most frequently consumed type of wine (red/rose/white), "Favourite" the preferred type of wine (red/rose/white), "Price" - the typical price of purchased wine, in lv. $(0-5,5-8,9-12,13-25,25+)$, "Foreign" - frequency of foreign wine purchases, times (0, 1-2, up to 10, frequently).

Tests (Kruskal-Wallis tests) about the influence of the favourite type of wine (red/rose/white) show that respondents have differences only about the year of production. The year of production is more important for the amateurs of red wines, with "large" size effect of 0.969, as shows the result of the Vargha and Delaney (2000) A test. This result is in line on the one hand with the common understanding in oenology that red wines are able to mature, and on the other hand the typical wine for Bulgaria is the red wine, therefore red wine amateurs are naturally viewed as "classical" consumers, who are expected to be more informed about the quality and features of wine.

\section{Conclusion}

The results of our study show that in their wine consumption, young Bulgarians are not differentiated by variables like sex, place where they live and living in couples or single.

Among the main sources of difference in the perceptions of young Bulgarians towards wine are their predisposition to buy expensive wines and the practice to mix wine drinking with drinking of other alcoholic beverages.

As a direction for future research, a comparison to perceptions of Bulgarians of higher ages could shed some light on intergenerational learning and whether there is a sustainable relationship between wine consumption of different generations, revealing the strength of tradition. The findings could be helpful for the elaboration of new wine brands, with new characteristics. 


\section{References}

1. Balabanova, D. and McKee, M., 1999. Patterns of alcohol consumption in Bulgaria. Alcohol and alcoholism, 34(4), pp.622-628.

2. Boneva, S., 2014. Effects of the increase of tobacco products excise on public health and budget revenues in EU. Economic Studies, 23(3), pp. 117-153.

3. Boshnakov, P. and Marinov, G., 2013. A Comparative Study Of Demand For Local And Foreign Wines In Bulgaria. Cross-Cultural Management Journal, 15(2), pp.5-10.

4. Castellini, A., Mauracher, C., Procidano, I., Sacchi, G., 2014. Italian market of organic wine: a survey on production system characteristics and marketing strategies. Wine Economics and Policy 2014 (3), pp.71-80.

5. Castellini, A. and Samoggia, A., 2018. Millennial consumers' wine consumption and purchasing habits and attitude towards wine innovation. Wine Economics and Policy, 7(2), pp.128-139.

6. de Winter, J.F.C. and Dodou, D., 2010. Five-Point Likert Items: t test versus Mann-Whitney-Wilcoxon (Addendum added October 2012). Practical Assessment, Research, and Evaluation, 15(1), Article 11, pp. 1-16.

7. Dimock, M., 2019. Defining generations: Where Millennials end and Generation Z begins. Pew Research Center, 17, pp.1-7.

8. Dolot, A., 2018. The characteristics of Generation Z. E-mentor, 74(2), pp.4450.

9. ISTAT (Instituto Nationale di Statistica), 2020. Il Consumo di Alcol in Italia. Anno 2019. https://www.istat.it/it/archivio/244222

10. Foroudi, P., Cuomo, M.T., Rossi, M. and Festa, G., 2019. Country-of-origin effect and millennials' wine preferences - a comparative experiment. British Food Journal, pp. 1-17.

11. Gunay, G. N., and Baker, M. J., 2011. The factors influencing consumers' behaviour on wine consumption in the Turkish wine market, EuroMed Journal of Business, 6(3), 2011, pp.324-341.

12. Kaneva, N. and Popescu, D., 2011. National identity lite: Nation branding in post-Communist Romania and Bulgaria. International journal of Cultural studies, 14(2), pp.191-207.

13. Kruskal, W. and Wallis, W., 1952. Use of Ranks in One-Criterion Variance Analysis, Journal of the American Statistical Association, 47(260), pp. 583-621.

14. Lyubenov, Z., Neykov, Y. and Vergilova, S., 2016. Internationalization of the wine industry companies in Bulgaria. Scientific Research Almanac, 23, pp. 1-14. 
15. Mann, H. B. and Whitney, D. R., 1947. On a Test of Whether one of Two Random Variables is Stochastically Larger than the Other, Annals of Mathematical Statistics 18(1), pp.50-60.

16. Nelgen, S. and Anderson, K., 2011. Global wine markets, 1961 to 2009: a statistical compendium. University of Adelaide Press.

17. Němcová, J. and Berčík, J., 2019. Neuromarketing and the decision-making process of the generation Y wine consumers in the Slovak Republic. Potravinarstvo Slovak Journal of Food Sciences, 13(1), pp.38-45.

18. Noev, N., 2005. Wine quality and regional reputation: hedonic analysis of the Bulgarian wine market. Eastern European Economics, 43(6), pp.5-30.

19. NSI, 2020a. https://www.nsi.bg/en/content/6656/ marriages-place-residence and-partners\%E2\%80\%99-age Marriages by place of residence and partners' age in 2019.

20. NSI, 2020b. https://www.nsi.bg/en/content/6481/unemployed-andunemploy ment-rates-national-level-statistical-regions

21. Unemployed and unemployment rates of population aged 15 years and over for the first quarter of 2020 .

22. NSI, 2020c. https://www.nsi.bg/en/content/6620/mean-age-mother-birthplace-residence-statistical-regions-and-districts.

23. OIV, 2019. 2019 Statistical report on world vitiviniculture, Paris: OIV (International organisation of vine and wine).

24. Priporas, C.V., Stylos, N. and Fotiadis, A. K., 2017. Generation Z consumers' expectations of interactions in smart retailing: A future agenda. Computers in Human Behavior, 77, pp.374-381.

25. Radovanović, V., Đorđević, D.Ž. and Petrović, J., 2017. Wine Marketing: Impact of Demographic Factors of Serbian Consumers On the Choice of Wine. Economic Themes, 55(2), pp.199-215.

26. Schewe, C.D. and Meredith, G., 2004. Segmenting global markets by generational cohorts: determining motivations by age. Journal of Consumer Behaviour: An International Research Review, 4(1), pp.51-63.

27. Stancu, A., 2015. An analysis of the relation between wine consumption and cultural models. Ekonomika poljoprivrede, 62(1), pp.207-227.

28. Szabó, Z., 2018. Event Marketing-The Driver of Wine Culture. Management Studies, 6(2), pp.121-126.

29. Szakál, Z., 2008. Market segmentation of Tokaj wine specialities with statistical method. In: Fatula, D., Management of the economic development. Chosen aspects, Krakow: Krakowskie Towarzystwo Edukacyjne, pp.279-287. 
30. Thach, L., Riewe, S. and Camillo, A., 2020. Generational cohort theory and wine: analyzing how gen $\mathrm{Z}$ differs from other American wine consuming generations. International Journal of Wine Business Research, ahead-of-print(ahead-of-print). https://doi.org/10.1108/IJWBR-12-2019-0061

31. Turner, A., 2015. Generation Z: Technology and social interest. The journal of individual Psychology, 71(2), pp.103-113.

32. Vannevel, M., Vink, N., Brand, J. and Panzeri, V., 2018. Marketing Pinotage to South African student millennials. International Journal of Wine Business Research, 30(3), pp.331-342.

33. Vargha, A. and Delaney, H.D., 2000. A critique and improvement of the CL common language effect size statistics of McGraw and Wong. Journal of Educational and Behavioral Statistics, 25(2), pp.101-132.

34. Vlachvei, A., 2011. Factors influencing consumers' behavior on wine consumption: a literature review. Journal of European Economy, 10(4), pp.425-443.

35. Wilcoxon, F., 1945. Individual comparisons by ranking methods, Biometrics Bulletin, 1(6), pp.80-83.

36. Williams, K.C. and Page, R.A., 2011. Marketing to the generations. Journal of Behavioral Studies in Business, 3, p.1.

37. Wood, S., 2013. Generation $\mathrm{Z}$ as consumers: trends and innovation. Institute for Emerging Issues: NC State University, pp.1-3.

38. Zaharieva, G., Iliev, D., Sarkisyan, K. and Stefanov, G., 2012. Bulgaria's foreign trade specialization and the firms' behaviour during the economic crisis. Dialog, 2012, pp. 140-156.

\section{Appendix}

The questionnaire

1. Sex.

2. Year of birth.

3. How many years do you live in a couple/marriage?

4. Where do you live?

5. How often do you buy wine from a supermarket or another shop?

6. The last wine you bought was? (country of origin)

7. What wine do you drink more often? (white/rose/red)

8. Did it happen for you to drink red wine to fish or chicken (they are traditionally consumed with white wine)? (yes/no)

9. Did it happen for you to drink white wine to beef or pork (they are traditionally consumed with red wine)? (yes/no) 
10. What type of wine do you prefer? (white dry/ rose dry/ red dry/ champagne/ fortified)

11. What is the price of the wine you buy most often?

12. How many times in the last year did you buy wine priced above $15 \mathrm{lv}$.?

13. How many times in the last year did you buy a bottle of foreign wine?

14. If you drink wine, there is no problem to drink also... (rakia/ vodka/ beer/ cognac/ other/ nothing).

15. When you buy wine in a supermarket to what extent are you influenced by: the variety. (Likert 5-point item)

16. When you buy wine in a supermarket to what extent are you influenced by: the country of origin. (Likert 5-point item)

17. When you buy wine in a supermarket to what extent are you influenced by: the type of the wine (dry/sweet). (Likert 5-point item)

18. When you buy wine in a supermarket to what extent are you influenced by: the price. (Likert 5-point item)

19. When you buy wine in a supermarket to what extent are you influenced by: the brand/the producer. (Likert 5-point item)

20. When you buy wine in a supermarket to what extent are you influenced by: the year. (Likert 5-point item)

21. When you buy wine in a supermarket to what extent are you influenced by: the occasion. (Likert 5-point item)

22. When you buy wine in a supermarket to what extent are you influenced by: the food. (Likert 5-point item)

23. When you buy wine in a supermarket to what extent are you influenced by: the type of wine (white/rose/red). (Likert 5-point item) 